\title{
Bowel Preparation for Colonoscopy
}

\author{
David E. Beck, M.D. ${ }^{1}$
}

\section{ABSTRACT}

Colonoscopy is the premier method for colonic evaluation and its diagnostic accuracy and therapeutic safety depends on the quality of the colonic cleansing. Bowel cleansing with polyethylene glycol and sodium phosphate provides cleansing with highquality preparations with an acceptably low morbidity rate and a high degree of patient satisfaction in a cost-effective manner. Modifications have reduced the volume of the polyethylene glycol preparations. Sodium phosphate has been associated with electrolyte and osmolarity imbalances and nephrocalcinosis; therefore, its clinical use has been questioned. Polyethylene glycol may be safer in patients with a history of significant renal, heart, or liver disease.

KEYWORDS: Bowel preparation, sodium phosphate, polyethylene glycol, colonoscopy

Objectives: On completion of this article, the reader should be able to summarize the methods for mechanical bowel preparation for colonoscopy.

Colonoscopy is the premier method for colonic evaluation and its diagnostic accuracy and therapeutic safety depends on the quality of the colonic cleansing. The ideal mechanical bowel preparation would reliably empty the colon of all fecal material in a rapid fashion with no gross or histologic alteration of the colonic mucosa. It would also not cause any patient discomfort or shifts in fluids or electrolytes and would be inexpensive. ${ }^{1,2} \mathrm{Un}$ fortunately, none of the preparations currently available meet all of these requirements. ${ }^{1-4}$ All current preparations use a combination of cleansing methods such as dietary restrictions and osmotic or stimulative laxatives (Table 1). Important aspects of each method will be described.

\section{CLEANSING METHODS}

\section{Dietary Restriction}

One to 5 days on a clear liquid or low residue diet reduces the amount of stool. However, this method by itself is insufficient to adequately cleanse the colon. Dietary restrictions are typically used the day prior to the planned procedure and clear liquids are used to maintain hydration following mechanical cleansing. Most regimes allow liquid oral intake up to 4 hours prior to sedation.

\section{Osmotic Agents}

Osmotic agents either retain water in the colon or pull water into the colon depending on their osmolality relative to tissue fluid. Common osmotic agents are nonabsorbed salts or metabolically inert compounds.

Polyethylene glycol electrolyte gastrointestinal lavage solution (PEG lavage) is an isosmotic solution composed of polyethylene glycol 3350 and an electrolyte solution (sodium $125 \mathrm{mmol} / \mathrm{L}$, sulfate $40 \mathrm{mmol} / \mathrm{L}$, chloride $35 \mathrm{mmol} / \mathrm{L}$, bicarbonate $20 \mathrm{mmol} / \mathrm{L}$, and potassium $10 \mathrm{mmol} / \mathrm{L}$ ). This solution is available commercially as GoLytely ${ }^{\circledR}$ (Braintree Laboratories, Holbrook,

\footnotetext{
${ }^{1}$ Department of Colon and Rectal Surgery, Ochsner Clinic Foundation, New Orleans, Louisiana.

Address for correspondence and reprint requests: David E. Beck, M.D., Department of Colon and Rectal Surgery, Ochsner Clinic Foundation, 1514 Jefferson Hwy., New Orleans, LA 70121 (e-mail: dbeckmd@aol.com).
}

Laparoscopy and Endoscopy; Guest Editor, David E. Beck, M.D.

Clin Colon Rectal Surg 2010;23:10-13. Copyright (C) 2010 by Thieme Medical Publishers, Inc., 333 Seventh Avenue, New York, NY 10001, USA. Tel: +1(212) 584-4662.

DOI: http://dx.doi.org/10.1055/s-0030-1247851.

ISSN 1531-0043. 


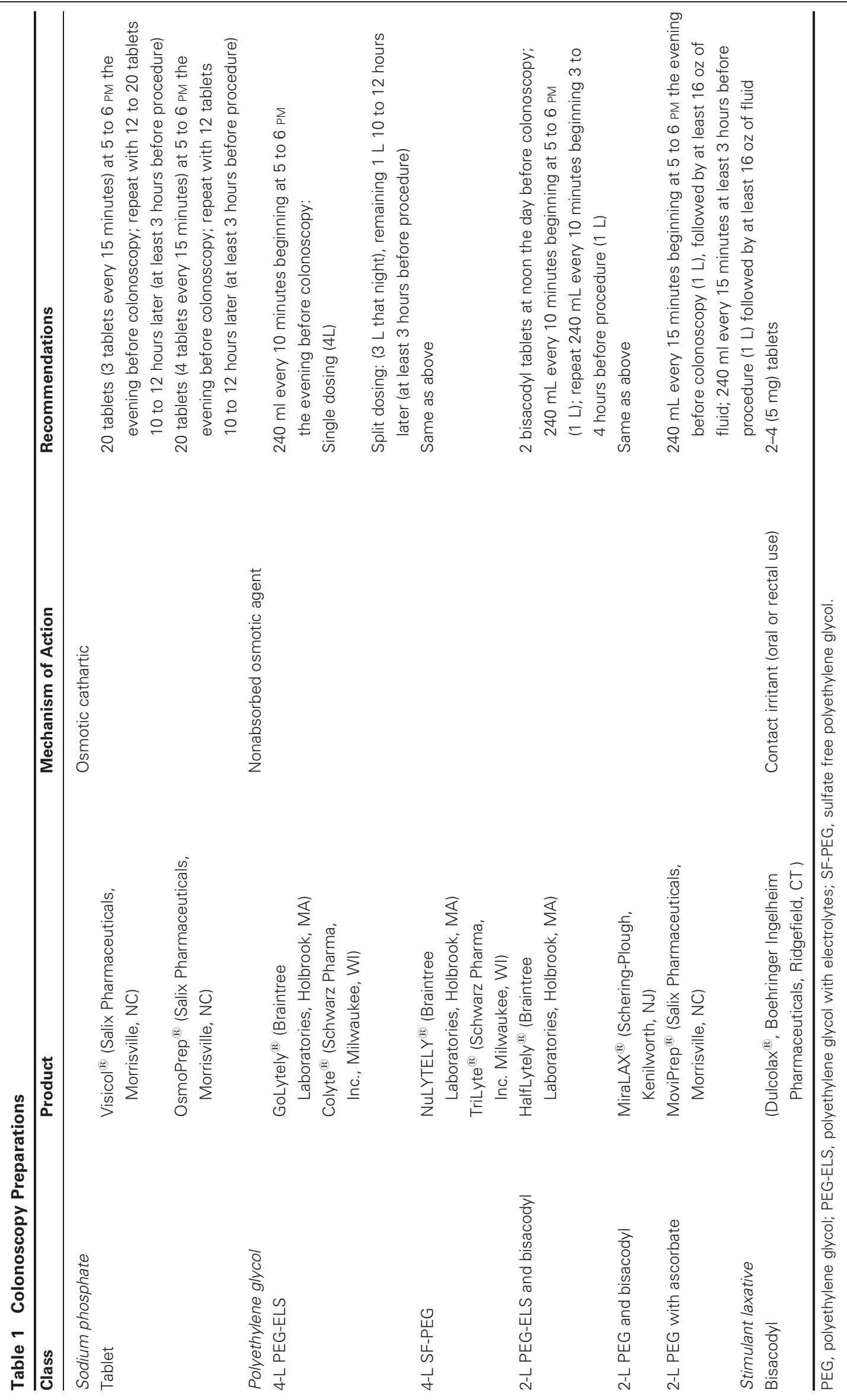


MA) and Colyte ${ }^{\circledR}$ (Schwarz Pharma, Inc., Milwaukee, WI). This preparation provides excellent cleansing (in 90 to $100 \%$ of patients), and is associated with no fluid or electrolyte problems. It has a mildly salty taste, is tolerated by patients, and multiple clinical trials have demonstrated its effectiveness. ${ }^{3-6}$ Although well tolerated, 5 to $15 \%$ of patients do not complete the preparation due to palatability or large volume. ${ }^{7,8}$

The timing of PEG lavage administration appears to affect the quality of cleansing. Divided or split-dose regimens (a part of the prep is given the night before and the remainder the morning of the procedure) have shown better cleansing and toleration than administering all of the preparation the day before. ${ }^{3}$ However, this adds to scheduling challenges. Another study showed that consumption of PEG lavage less than 5 hours before the procedure resulted in better cleansing than when it was given more than 19 hours before the procedure. ${ }^{9}$ The addition of prokinetic agents (metoclopramide) or stimulants (bisacodyl) has not improved patient tolerance or cleansing with 4-L PEG lavage. ${ }^{3}$ PEG lavage is relatively safe for patients with electrolyte imbalance or fluid changes (renal failure, congestive heart failure, or liver disease with ascites) and is the method of choice for infants and children. ${ }^{3}$

This solution is now available in several flavors (e.g., pineapple, cherry) and as a slightly modified solution with no sodium sulfate for improved taste $\left(\right.$ NuLytely ${ }^{\circledR}$, Braintree Laboratories, TriLyte $^{\circledR}$, Schwarz Pharma). ${ }^{10}$ Newer reduced volume options have been described to improve patient tolerance. Ten to twenty $\mathrm{mg}$ of bisacodyl are administered and followed in 4 to 6 hours with 2 liters of PEG lavage with electrolytes (Halflightly ${ }^{\circledR}$, Braintree Laboratories) or without electrolytes (Miralax ${ }^{\circledR}$, Braintree Laboratories) at doses of $240 \mathrm{~mL}$ (8 oz) every 10 minutes. Multiple studies comparing full-volume $(4 \mathrm{~L})$ to low-volume (2 L) PEG lavage preparations have demonstrated equal cleansing, but better tolerance with the low volumes. ${ }^{3}$

Another variation is a hypertonic PEG lavage solution with electrolytes and ascorbic acid (MoviPrep ${ }^{\mathbb{R}}$, Salix Pharmaceuticals, Morrisville, NC). ${ }^{11}$ Two liters of the solution are administered in single or split dosage regimens followed by clear liquids.

Sodium phosphate is a hyperosmotic agent, which is available in liquid and tablet form. Aqueous sodium phosphate $\left(\right.$ Fleet $^{\mathrm{R}}$, CB Fleet, Lynchburg, VA) is a lowvolume preparation that draws water into the bowel lumen to promote cleansing. Significant fluid and electrolyte changes can occur. ${ }^{3}$ Sodium phosphate is diluted to prevent emesis and significant oral fluid is necessary to prevent dehydration. Some patients with compromised renal function, dehydration, hypercalcemia, or hypertension who use angiotensin-converting enzyme (ACE) inhibitors or angiotensin receptor blockers (ARBs) have experienced phosphate nephropathy with the use of sodium phosphate. ${ }^{12}$ The renal impairment seems to be age and dose related and is not always reversible. ${ }^{3}$ This potential adverse effect with higher doses of sodium phosphate has led to the bowel preparation product being voluntarily withdrawn by the manufacturer as an over the counter product. It remains available as a prescription product but its future is uncertain. Dosing includes two doses of 30 to $45 \mathrm{~mL}$ of the oral solution at least 10 to 12 hours apart. Each dose is taken with at least 8 ounces of liquid followed by an additional 16 ounces of liquid. Sodium phosphate preparations have been also associated with aphthoid lesions in the colon. This may limit the usefulness of this preparation in patients undergoing colonoscopy for inflammatory bowel disease.

Tablet sodium phosphate preparations (sodium phosphate monobasic monohydrate with sodium phosphate dibasic anhydrate, Visicol TM, Inkine Pharmaceutical, Blue Bell, PA) involve the ingestion of 32 to 40 tablets. Twenty tablets are ingested on the evening before the procedure and 12 to 20 tablets on the day of the procedure (3-5 hours before). The 20 tablets are taken as 4 tablets every 15 minutes with 8 ounces of clear liquids. ${ }^{13,14} \mathrm{~A}$ recent modification by the manufacturer (OsmoPrep ${ }^{\circledR}$, Salix Pharmaceuticals, Morrisville, NC) has reduced the size of the tablet. Bisacodyl has also been used as an adjunct by some physicians.

The Federal Drug Administration has included a Black Box warning with sodium phosphate products. This along with the need to consume a significant number of tablets has limited the adoption of this method. Over 16 studies of bowel preparations have shown that sodium phosphate produces bowel cleansing equivalent to PEG lavage with improved patient tolerance. ${ }^{15-18}$

\section{Stimulate Agents}

Cathartic or stimulate agents cause bowel wall contractions which produce evacuation. Regimens using these medications usually require 2 to 2 days to empty the colon of stool and are frequently combined with enemas and dietary restrictions. Cathartics have been associated with dehydration and electrolyte changes. In controlled trials using cathartics alone, adequate cleansing occurs in only 75 to $80 \%$ of patients.

\section{ADJUNCTIVE MEASURES}

\section{Enemas}

Enemas (saline solution, soapsuds, tap water) work by dilution or irritation. They are messy and uncomfortable for patients and the nursing staff. They rarely provide adequate cleansing when used alone, but may be helpful in patients who present to endoscopy with inadequate cleansing. 


\section{SUMMARY}

Several options are available to prepare patients for colonoscopy. Knowledge of the various options, along with their associated advantages and limitations, allows providers to choose the appropriate preparation for individual patients. As the quality of cleansing is roughly similar, the endoscopist's experience, patient preference and compliance seem to be major factors in the option selected. Each product manufacturer provides detailed instruction for their product. Current guidelines for colonoscopic bowel preparation have been produced by a task force from the American Society of Colon and Rectal Surgeons (ASCRS), the American Society for Gastrointestinal Endoscopy (AGE), and the Society of American Gastrointestinal and Endoscopic Surgeons (SAGES). ${ }^{3}$

Further research and studies will suggest preparations that will come closer to our ideals.

\section{REFERENCES}

1. DiPalma JA, Brady CE III. Colon cleansing for diagnostic and surgical procedures: polyethylene glycol-electrolyte lavage solution. Am J Gastroenterol 1989;84(9):1008-1016

2. Tooson JD, Gates LK Jr. Bowel preparation before colonoscopy. Choosing the best lavage regimen. Postgrad Med 1996;100(2):203-204, 207-212, 214

3. Wexner SD, Beck DE, Baron TH, Fanelli RD, Hymann N, Shen B, Wasco K. A consensus document on bowel preparation before colonoscopy: prepared by a task force from the American Society of Colon and Rectal Surgeons (ASCRS), the American Society of Gastrointestinal Endoscopy (ASGE), and the Society of American Gastrointestinal and Endoscopic Surgeons (SAGES). Gastrointest Endosc 2006;63(7):894-909

4. Beck DE. Mechanical bowel cleansing for surgery. Perspect Colon Rectal Surg 1994;7:97-114

5. Beck DE, Fazio VW, Jagelman DG. Comparison of oral lavage methods for preoperative colonic cleansing. Dis Colon Rectum 1986;29(11):699-703

6. Davis GR, Santa Ana CA, Morawski SG, Fordtran JS. Development of a lavage solution associated with minimal water and electrolyte absorption or secretion. Gastroenterology 1980;78(5 Pt 1):991-995
7. Golub RW, Kerner BA, Wise WE Jr, et al. Colonoscopic bowel preparations-which one? A blinded, prospective, randomized trial. Dis Colon Rectum 1995;38(6):594-599

8. Marshall JB, Pineda JJ, Barthel JS, King PD. Prospective, randomized trial comparing sodium phosphate solution with polyethylene glycol-electrolyte lavage for colonoscopy preparation. Gastrointest Endosc 1993;39(5):631-634

9. Church JM. Effectiveness of polyethylene glycol antegrade gut lavage bowel preparation for colonoscopy-timing is the key!. Dis Colon Rectum 1998;41(10):1223-1225

10. Beck DE, DiPalma JA. A new oral lavage solution vs cathartics and enema method for preoperative colonic cleansing. Arch Surg 1991;126(5):552-555

11. Worthington J, Thyssen M, Chapman G, Chapman R, Geraint M. A randomised controlled trial of a new 2 litre polyethylene glycol solution versus sodium picosulphate + magnesium citrate solution for bowel cleansing prior to colonoscopy. Curr Med Res Opin 2008;24(2):481-488

12. Markowitz GS, Stokes MB, Radhakrishnan J, D’Agati VD. Acute phosphate nephropathy following oral sodium phosphate bowel purgative: an underrecognized cause of chronic renal failure. J Am Soc Nephrol 2005;16(11):3389-3396

13. Aronchick CA, Lipshutz WH, Wright SH, Dufrayne F, Bergman G. A novel tableted purgative for colonoscopic preparation: efficacy and safety comparisons with Colyte and Fleet Phospho-Soda. Gastrointest Endosc 2000;52(3):346-352

14. Rex DK, Schwartz H, Goldstein M, et al. Safety and coloncleansing efficacy of a new residue-free formulation of sodium phosphate tablets. Am J Gastroenterol 2006;101(11):25942604

15. Cohen SM, Wexner SD, Binderow SR, et al. Prospective, randomized, endoscopic-blinded trial comparing precolonoscopy bowel cleansing methods. Dis Colon Rectum 1994; 37(7):689-696

16. Vanner SJ, MacDonald PH, Paterson WG, Prentice RS, Da Costa LR, Beck IT. A randomized prospective trial comparing oral sodium phosphate with standard polyethylene glycol-based lavage solution (Golytely) in the preparation of patients for colonoscopy. Am J Gastroenterol 1990;85(4): 422-427

17. Vanner SJ, MacDonald PH, Paterson WG, Prentice RS, Da Costa LR, Beck IT. A randomized prospective trial comparing oral sodium phosphate with standard polyethylene glycol-based lavage solution (Golytely) in the preparation of patients for colonoscopy. Am J Gastroenterol 1990;85(4): $422-427$

18. Zmora O, Wexner SD. Bowel preparation for colonoscopy. Clin Colon Rectal Surg 2001;14:309-316 